\title{
Finite-element-based design optimisation of a novel high flexion knee used in total knee arthroplasty
}

\author{
Sudesh Sivarasu* and Lazar Mathew \\ School of Biotechnology, Chemical \& Biomedical Engineering, VIT University, Vellore, India - 632014
}

(Received 12 October 2008; final version received 9 November 2008)

\begin{abstract}
The application of finite-element modelling in medical applications has been evolving as a field of high importance in recent times. Total knee arthroplasty (TKA) has been in existence for over 6 decades. The generic artificial knee implants used in the TKA have a restricted range of motion of around 90 degrees. A new design allowing a flexion extension range of over 120 degrees was designed and is used for analysis. Loading conditions of 10 times the body weight are considered. The finite-element analyses of the designs were carried out based on standard biomaterials used in orthopaedic implants. The results of the analyses were used in identifying areas of extreme stress within the design and the spots prone to higher deformation. On the basis of these results slight modification of the designs was carried out. The results are also verified whether the body is within the linear deformation levels. The results obtained were very satisfactory and based on these results the models have been recommended for prototyping.
\end{abstract}

Keywords: artificial knee; total knee arthroplasty; finite-element modelling; biomaterials; design optimisation

\section{Background}

The joint replacement surgeries are doubtlessly a gift of science and technology for human welfare. The history of joint replacement begins way back in the late fifties. Initially the hip, then the knee and now shoulders, ankles, elbows, and almost all the joints are replaced nowadays.

Knee replacement procedures have been followed for almost 50 years in the surgical procedure called the total knee replacement (TKR) or the total knee arthroplasty (TKA). Here the cartilage and the bones which have been degenerated by arthritis are removed and replaced with metal components either using cemented or cementless procedures (Raymond et al. 2005; Karsh and Ploeg 2005). The metal and the polyethylene components are together called the artificial knee (Vilegas et al. 2004).

A thin layer of bone is removed from the damaged surface of the femur (thigh bone) by using special instruments. The removed bone is then replaced by a thin layer of metal, approximately of the same thickness as the bone that was removed. In a similar fashion the upper end of the tibia (shin bone) is removed and is replaced with a wafer of plastic. The back part of the kneecap (patella) may also be resurfaced with a piece of plastic. This procedure is called total knee arthroplasty (TKA).

\section{Components of an artificial knee}

The components in the artificial knee are:
- The femoral component

- The tibial component

- The patellar component

- The PE insert

The design of each of the components of the artificial knee is shown overleaf.

\subsection{Artificial knee}

In this procedure up to three bone surfaces may be replaced during the total replacement of the knee: the lower ends (condyles) of the thighbone, the top surface of the shinbone, and the back surface of the kneecap. Components are designed so that metal always articulates against plastic, which provides smooth movement and results in minimal wear as shown in Figure 1.

\section{Novel high flexion knee design}

A novel design of an artificial knee was developed using computer 3D modelling. The high flexion knee is obtained by using a multi-radii design pattern. The final increase of 20 degrees in flexion is obtained by increasing the condylar radii of curvature. (Sivarasu and Mathew 2007). Two models of the high flexion knee were developed and one of the models is subjected to finite element modelling. The two novel designs are shown in Figures 2 and 3.

*Corresponding author. Email: sudeshsivarasu@yahoo.co.in 
Table 1. Materials in artificial knee components.

- Femoral component

- Tibial component

- Patellar component

- Meniscal insert

- Metal

- Metal

- Polyethylene

- Polyethylene

Table 2. Biomaterials selection for FE analysis.

- Femoral component

- Tibial component

- Patellar component

- Meniscal insert

- Metal

- Metal

- Polyethylene

- Polyethylene
- SS 316 alloy

- SS 316 alloy

- UHMWPE

- UHMWPE

Table 3. SS 316-material composition.

\begin{tabular}{lccccccccc}
\hline Components & $\mathrm{C}$ & $\mathrm{Cr}$ & $\mathrm{Fe}$ & $\mathrm{Mn}$ & $\mathrm{Mo}$ & $\mathrm{Ni}$ & $\mathrm{P}$ & $\mathrm{S}$ & $\mathrm{Si}$ \\
\hline Wt. (\%) & 0.03 & 17 & 65 & 2 & 2.5 & 12 & 0.045 & 0.03 & 1 \\
\hline
\end{tabular}

Table 4. Physical properties of SS 316 alloy.

\section{Density}

Hardness rockwell

Tensile strength, ultimate

Tensile strength, yield

Modulus of elasticity

Elongation at break

Specific heat capacity

Table 5. Loading conditions for FEA of artificial knee.

\begin{tabular}{lc}
\hline Maximum load & $10 \times$ Body weight \\
\hline Average body weight & $70 \mathrm{Kg}$ (Sivarasu and Mathew, \\
& $2007)$ \\
Maximum load & $70 \times 10=700 \mathrm{Kg}$ \\
Maximum load on single & $700 \mathrm{Kg}$ (considering the patient \\
knee & standing in single leg) \\
\hline
\end{tabular}

Table 6. Femoral component description.

\begin{tabular}{lcccc}
\hline No. & Body name & Material & Mass & Volume \\
\hline 1 & Femoral component & SS 316 L & $0.59454 \mathrm{lb}$ & $2.10985 \mathrm{in}^{3}$ \\
\hline
\end{tabular}

Table 7. Femoral component meshing information.

\begin{tabular}{lc}
\hline Jacobian check: & 4 Points \\
\hline Element size: & $3.2565 \mathrm{~mm}$ \\
Tolerance: & $0.16283 \mathrm{~mm}$ \\
Quality: & High \\
Number of elements: & 83,722 \\
Number of nodes: & 129,670 \\
\hline
\end{tabular}

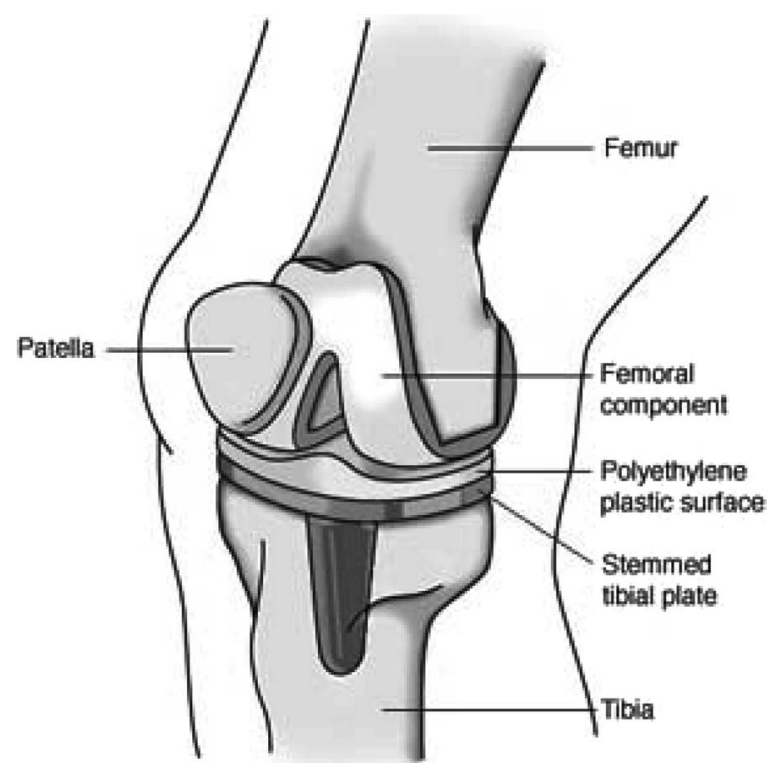

Figure 1. Knee implant components.

\section{Biomaterial selection}

The compositions of components in the artificial knee are shown in Table 1.

The metal considered for the analyses are shown in Table 2.

\subsection{SS 316 alloy}

The success of stainless steel is based on the fact that it has one unique advantage. The chromium in the stainless steel has a great affinity for oxygen, and forms a molecular level film of chromium oxide on the surface of the steel. The film itself is about 130 angstroms in thickness. Stainless steel has good strength and resists corrosion and oxidation well at elevated temperatures. The alloy

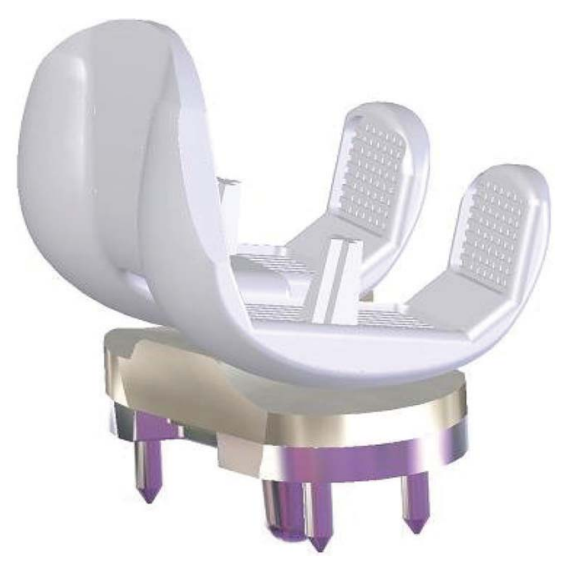

Figure 2. Model-I: regular conical insert. 
Table 8. Static displacement results.

\begin{tabular}{|c|c|c|c|c|c|}
\hline Name & Type & Min & Location & Max & Location \\
\hline \multirow[t]{2}{*}{ Displacement } & $\begin{array}{l}\text { Resultant } \\
\text { displacement }\end{array}$ & $0 \mathrm{~m}$ & $\begin{array}{l}(19.5784 \mathrm{~mm}, \\
35.3416 \mathrm{~mm}, \\
-18.0131 \\
\mathrm{~mm})\end{array}$ & $1.37082 \mathrm{e}-006 \mathrm{~m}$ & $\begin{array}{l}(-10.3415 \mathrm{~mm} \text {, } \\
28.3411 \mathrm{~mm}, \\
-9.02658 \\
\mathrm{~mm})\end{array}$ \\
\hline & & Node: 16 & & Node: 65,906 & \\
\hline
\end{tabular}

Table 9. Static strain results.

\begin{tabular}{|c|c|c|c|c|c|}
\hline Name & Type & Min & Location & Max & Location \\
\hline \multirow[t]{2}{*}{ Strain } & $\begin{array}{l}\text { Equivalent } \\
\text { strain }\end{array}$ & $2.94086 \mathrm{e}-010$ & $\begin{array}{l}(25.9452 \mathrm{~mm} \text {, } \\
4.86378 \mathrm{~mm} \text {, } \\
-26.2428 \\
\mathrm{~mm})\end{array}$ & $8.26513 \mathrm{e}-005$ & $\begin{array}{l}(-3.91515 \mathrm{~mm}, \\
32.005 \mathrm{~mm}, \\
-25.4337 \\
\mathrm{~mm})\end{array}$ \\
\hline & & Element: 69,36 & & Element: 20,012 & \\
\hline
\end{tabular}

Table 10. Max. von Mises stress results.

\begin{tabular}{lccccc}
\hline Name & Type & Min & Location & Max & Location \\
\hline \multirow{2}{*}{ Stress } & VON: von & $45.1611 \mathrm{~N} / \mathrm{m}^{2}$ & $(24.75 \mathrm{~mm}, 5.38$ & $2.18686 \mathrm{e}+007$ & $(-10.9919 \mathrm{~mm}$, \\
& Mises stress & & $\mathrm{mm},-26.8911$ & $\mathrm{~N} / \mathrm{m}^{2}$ & $27.323 \mathrm{~mm}$, \\
& & $\mathrm{mm})$ & Node: 8438 & $-9 \mathrm{~mm})$ \\
& Node: 67192 & & \\
\hline
\end{tabular}

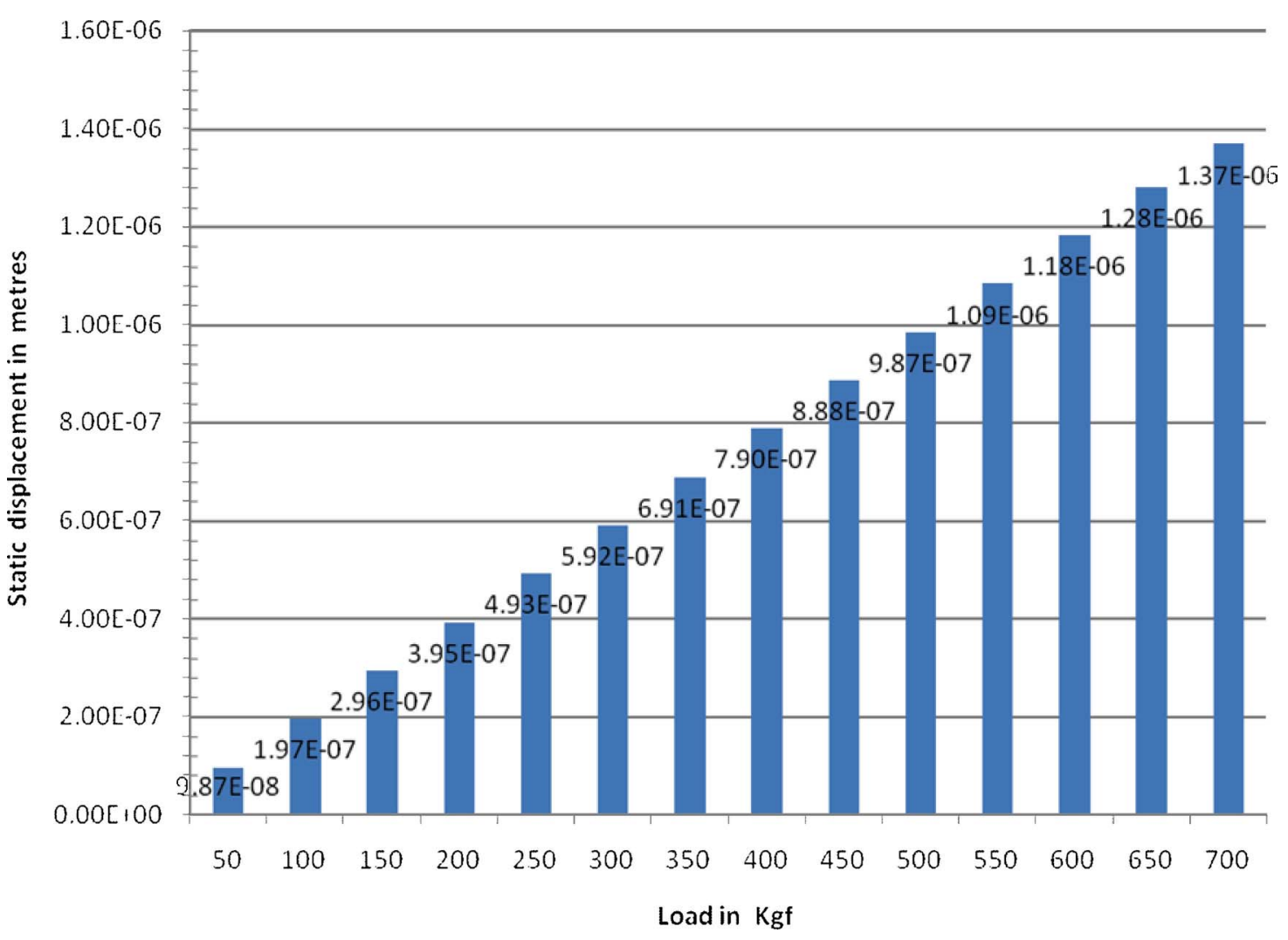

Chart 1. Displcement vs load applied. 


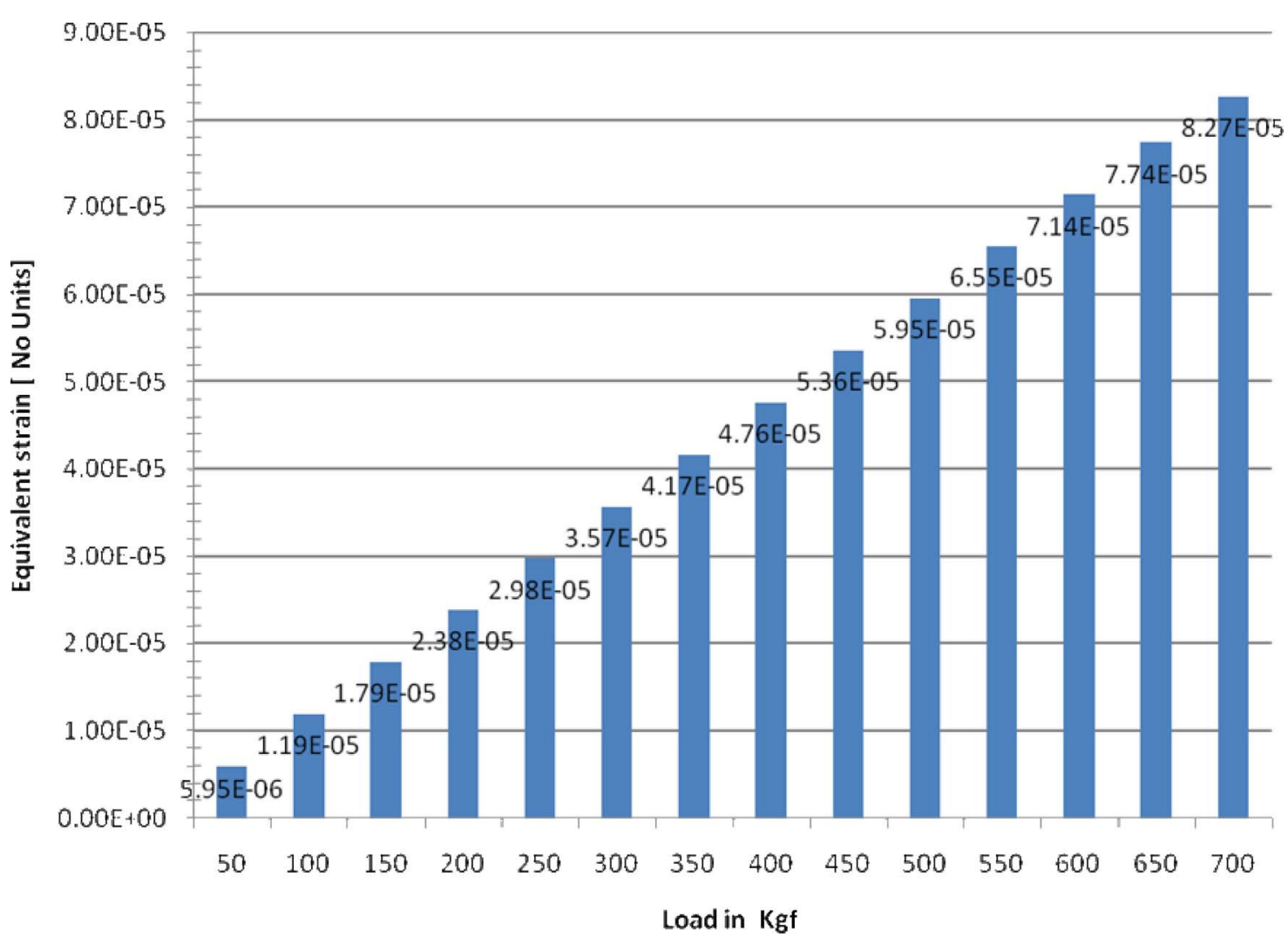

Chart 2. Equivalent strian vs applied load.

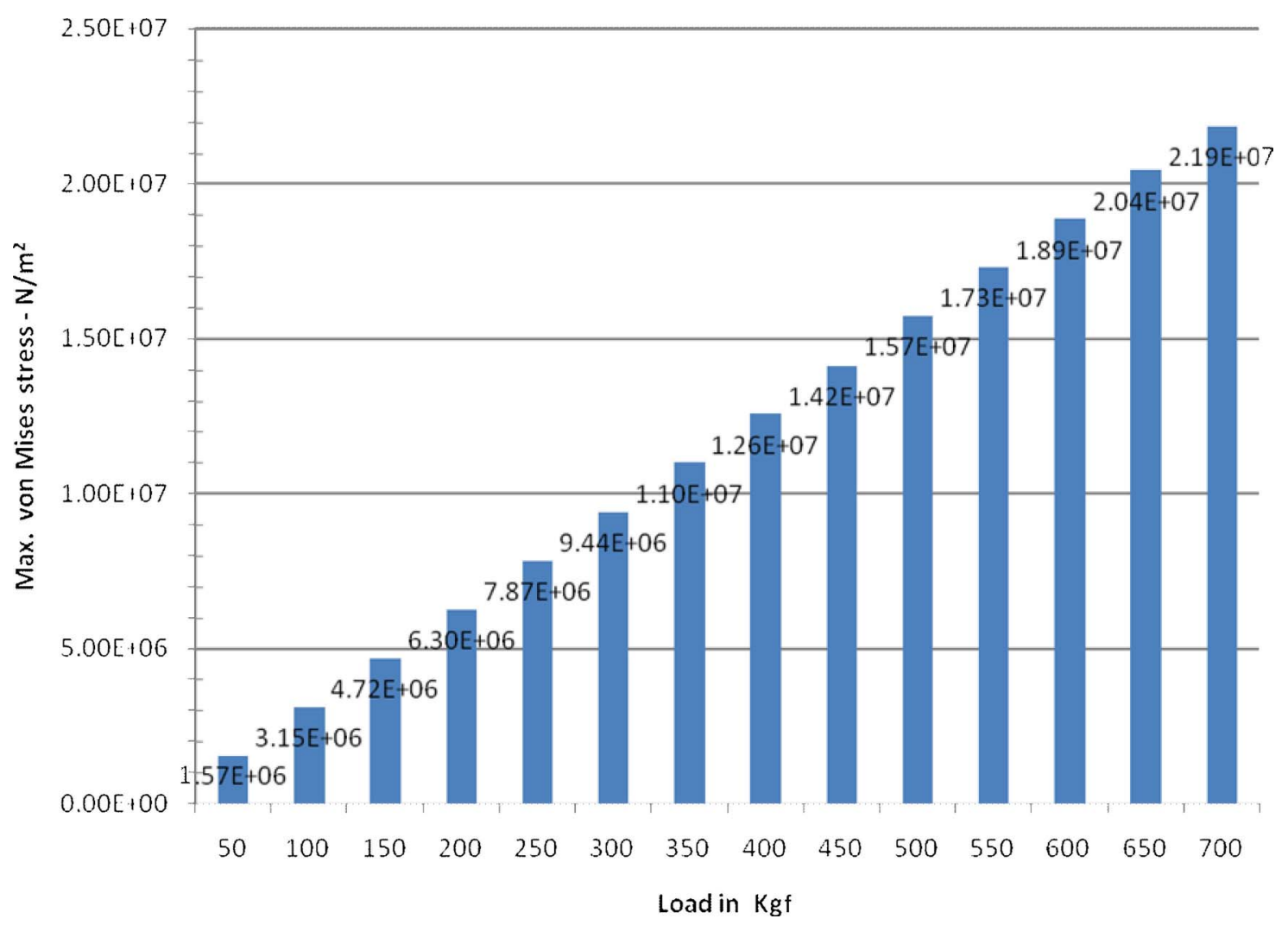

Chart 3. Max. von Mises stress vs applied load. 
Table 11. Tibial component description.

\begin{tabular}{llccc}
\hline No. & Body name & Material & Mass & Volume \\
\hline 1 & Tibial & SS316L & $0.226534 \mathrm{lbs}$ & $\begin{array}{c}1.32013 \\
\mathrm{e}-005 \mathrm{~m}^{3}\end{array}$ \\
\hline
\end{tabular}

Table 12. Tibial component meshing information.

\begin{tabular}{ll}
\hline Jacobian check: & 4 Points \\
\hline Element size: & $2.3643 \mathrm{~mm}$ \\
Tolerance: & $0.11822 \mathrm{~mm}$ \\
Quality: & High \\
Number of elements: & 9178 \\
Number of nodes: & 15,112 \\
\hline
\end{tabular}

of stainless steel used in medical applications is stainless steel 316 (SS 316), the material composition and physical properties of which are shown in Tables 3 and 4, respectively.

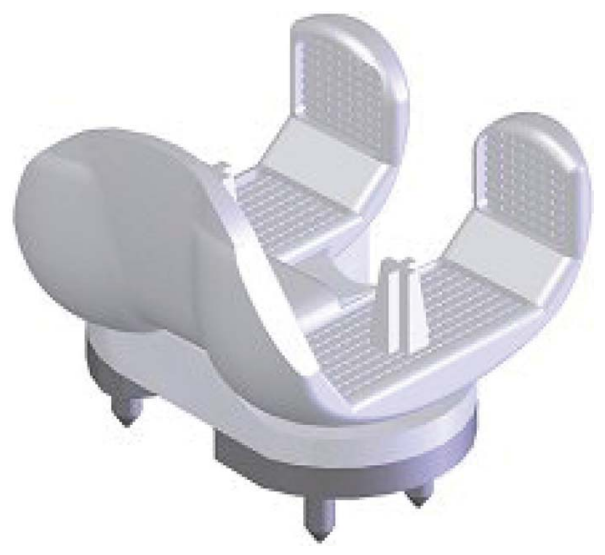

Figure 3. Model-II: peg restrainer for the PE insert.

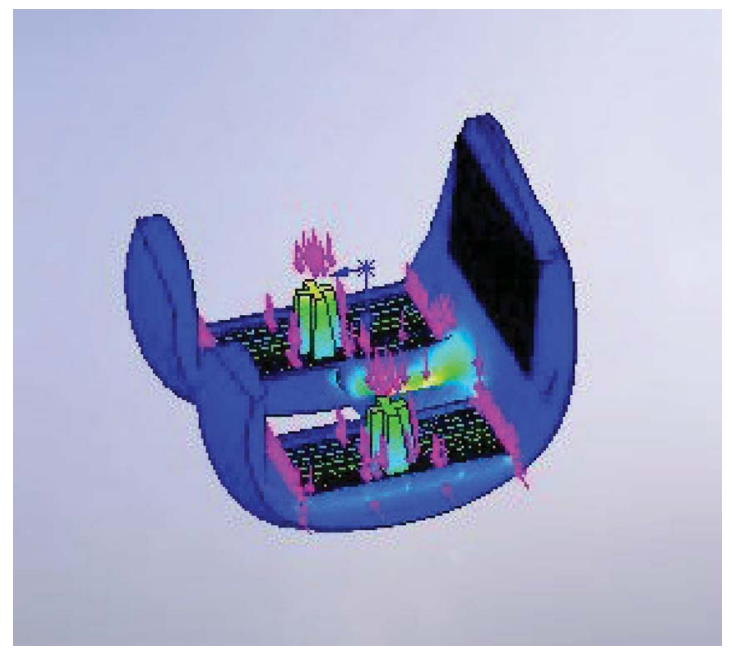

Figure 4. Static nodal stress - femoral component.

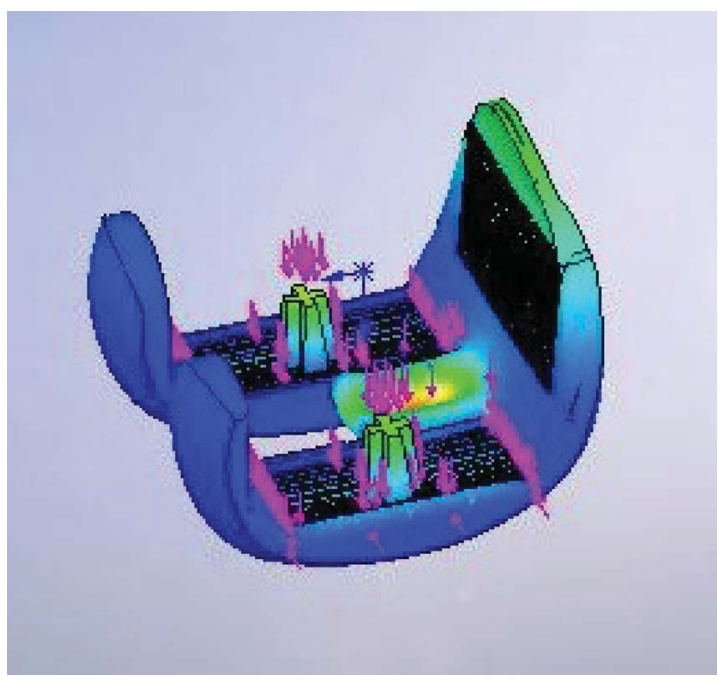

Figure 5. Static displacement - femoral component.

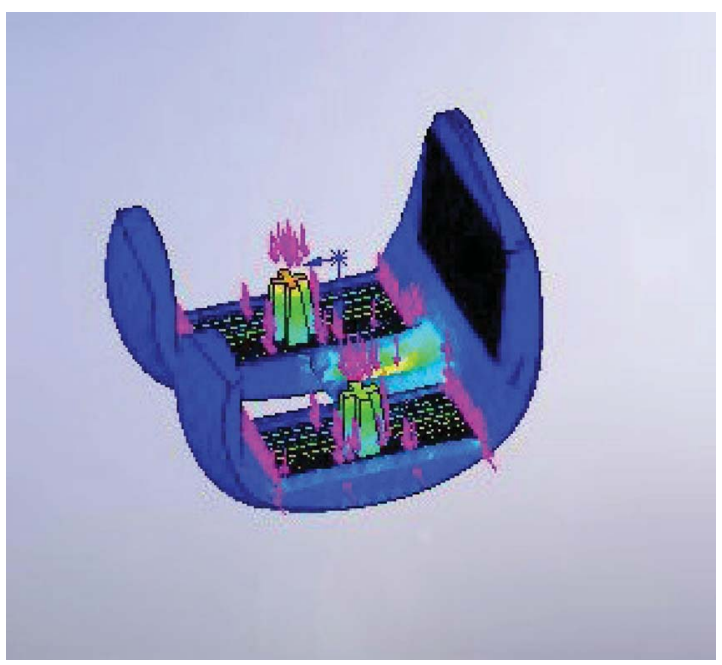

Figure 6. Static strain - femoral component.

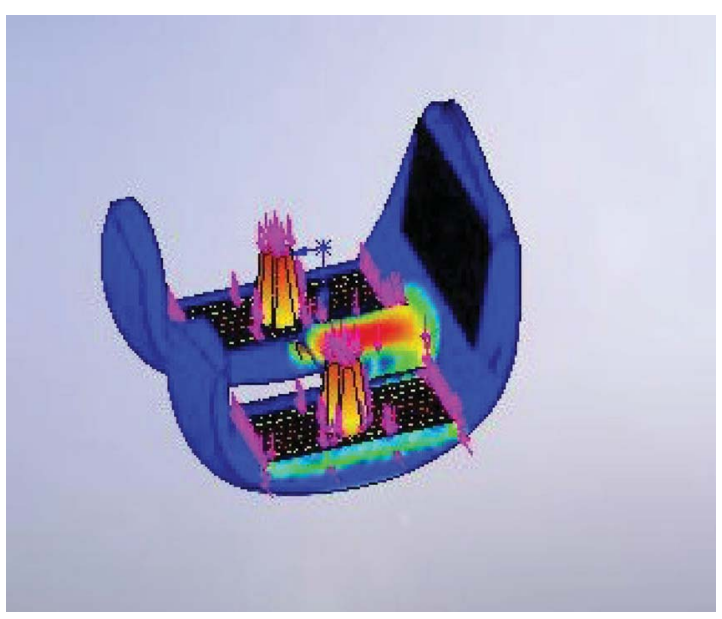

Figure 7. Max. von Mises stress - femoral component. 


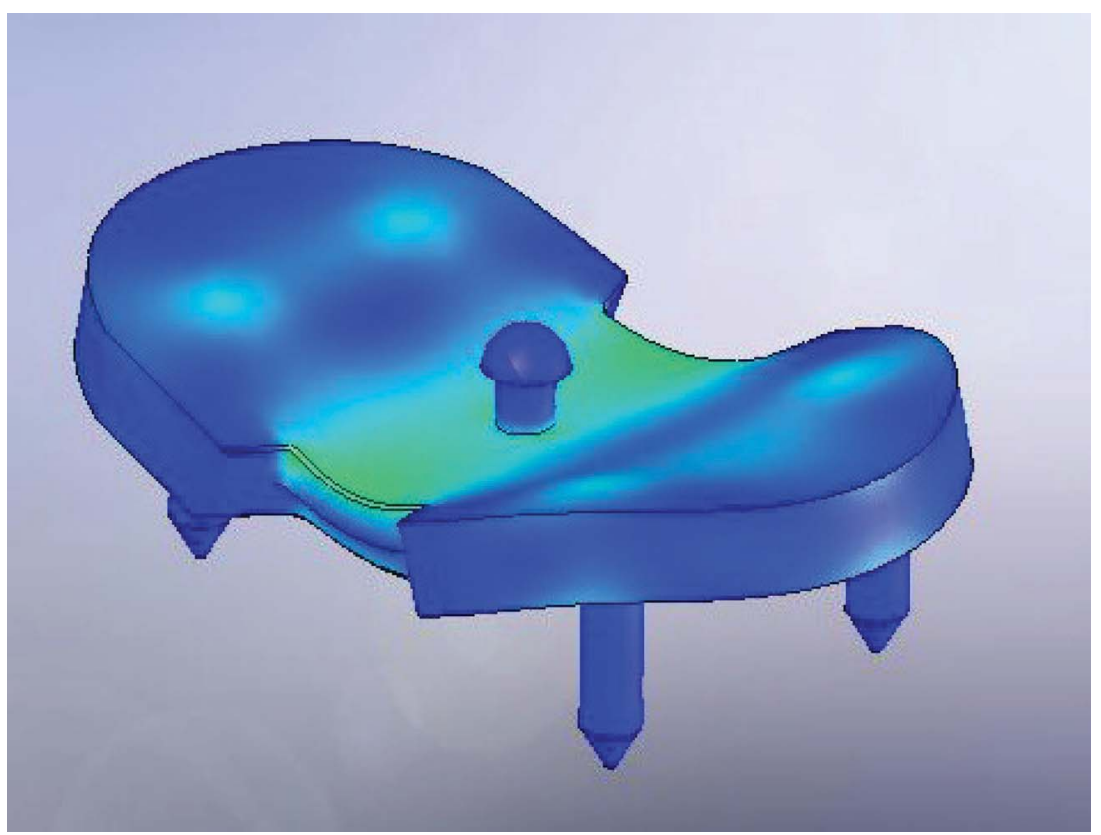

Figure 8. Static nodal stress - tibial component.

\subsection{UHMWPE}

UHMWPE is a linear polyolefin resin with a molecular weight approximately 10 times that of high molecular weight and high-density polyethylene (HMW HDPE) resins. The extremely high molecular weight of the resin (4 to 5 million) yields several unique properties including an excellent combination of superior abrasion resistance and impact strength. The low coefficient of friction results in self-lubricating, non-stick surfaces.

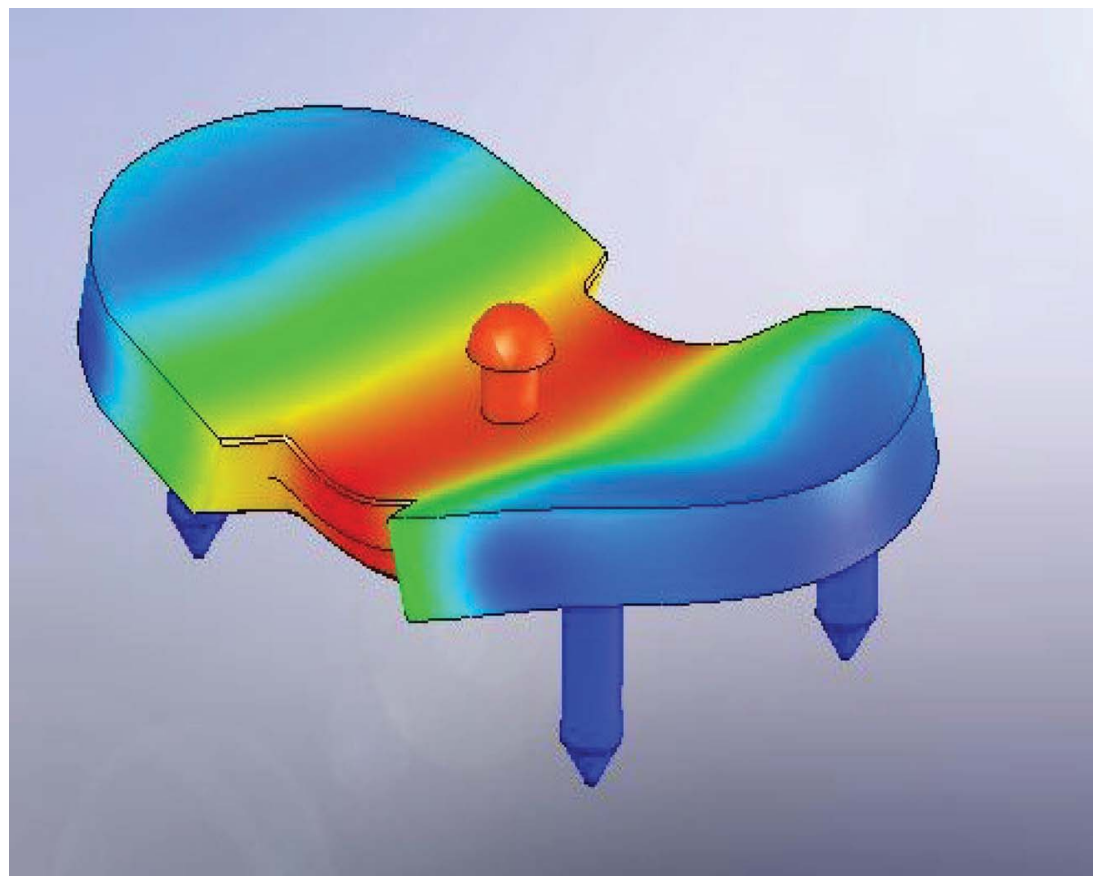

Figure 9. Static displacement - tibial component. 
Table 13. Static displacement results.

\begin{tabular}{|c|c|c|c|c|c|}
\hline Name & Type & Min & Location & Max & Location \\
\hline \multirow[t]{2}{*}{ Displacement } & $\begin{array}{l}\text { Resultant } \\
\text { displacement }\end{array}$ & $0 \mathrm{~m}$ & $\begin{array}{l}(10.0197 \mathrm{~mm}, \\
17 \mathrm{~mm}, \\
13.5625 \mathrm{~mm})\end{array}$ & $\begin{array}{l}1.39789 \mathrm{e}-005 \\
\mathrm{~m}\end{array}$ & $\begin{array}{l}(33.1183 \mathrm{~mm}, 3 \\
\mathrm{mm},-15.1537 \\
\mathrm{~mm})\end{array}$ \\
\hline & & Node: 34 & & Node: 1265 & \\
\hline
\end{tabular}

Table 14. Static strain results.

\begin{tabular}{|c|c|c|c|c|c|}
\hline Name & Type & Min & Location & Max & Location \\
\hline \multirow[t]{2}{*}{ Strain } & $\begin{array}{l}\text { Equivalent } \\
\text { strain }\end{array}$ & $6.6565 \mathrm{e}-009$ & $\begin{array}{c}(52.9948 \mathrm{~mm} \text {, } \\
19.8844 \mathrm{~mm} \text {, } \\
8.0946 \mathrm{~mm})\end{array}$ & 0.000799011 & $\begin{array}{c}(14.1853 \mathrm{~mm} \text {, } \\
5.5258 \mathrm{~mm} \\
11.231 \mathrm{~mm})\end{array}$ \\
\hline & & Element: 7640 & & Element: 2770 & \\
\hline
\end{tabular}

Table 15. Max. von Mises stress results.

\begin{tabular}{lccccc}
\hline Name & Type & Min & Location & Max & Location \\
\hline Stress & VON: von & $915.49 \mathrm{~N} / \mathrm{m}^{2}$ & $(52.3826 \mathrm{~mm}$, & $1.77698 \mathrm{e}+008$ & $(14.6547 \mathrm{~mm}$, \\
& Mises stress & & $19.4178 \mathrm{~mm}$, & $\mathrm{N} / \mathrm{m}^{2}$ & $5.31745 \mathrm{~mm}$, \\
& & $8.32522 \mathrm{~mm})$ & Node: 14,577 & $12.2757 \mathrm{~mm})$ \\
\hline
\end{tabular}

\section{Finite-element modelling of the artificial knee}

Finite element analysis (FEA) has become commonplace in recent years, and is now the basis of a multibillion dollar per year industry. Numerical solutions to even very complicated stress problems can now be routinely obtained using
FEA, and the method is so important that even introductory treatments of mechanics of materials - such as this modulus - should outline its principle features.

Perhaps the most important function of theoretical modelling is that of sharpening the designer's intuition. Finite

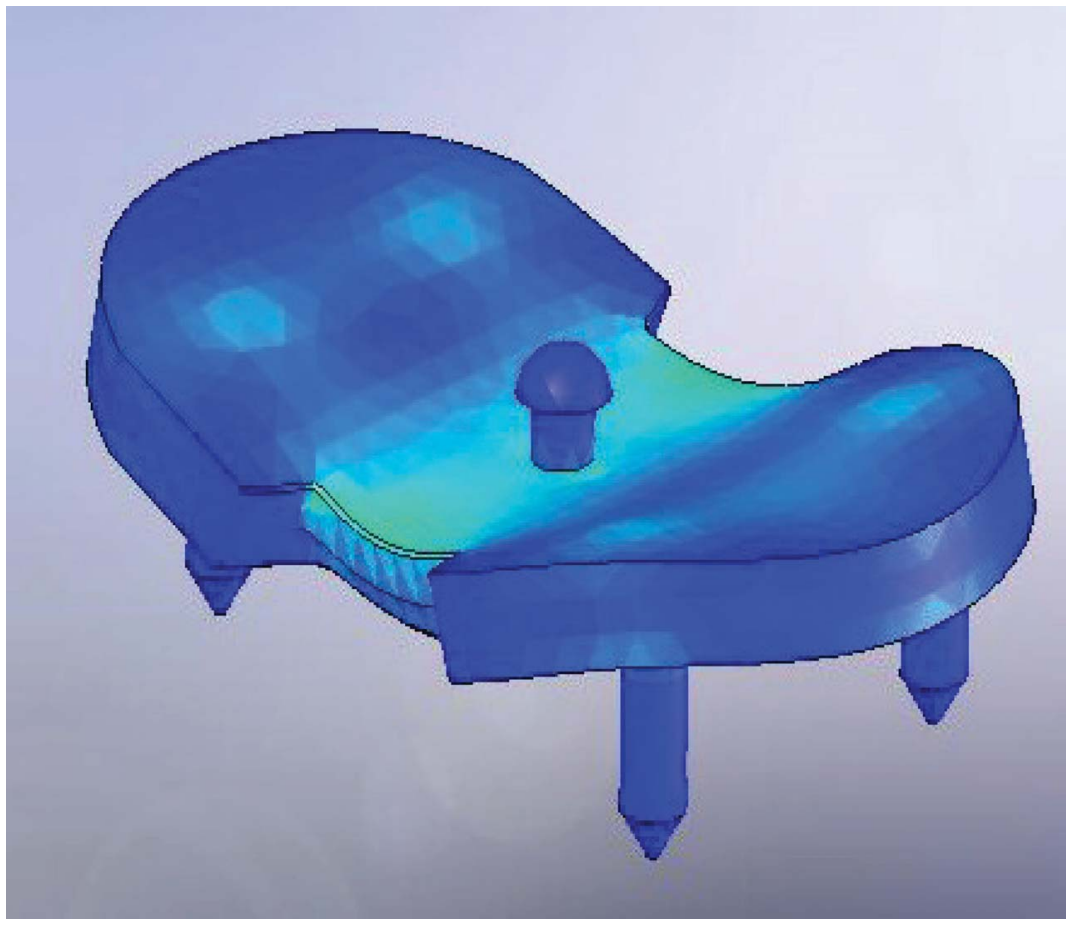

Figure 10. Static strain - tibial component. 


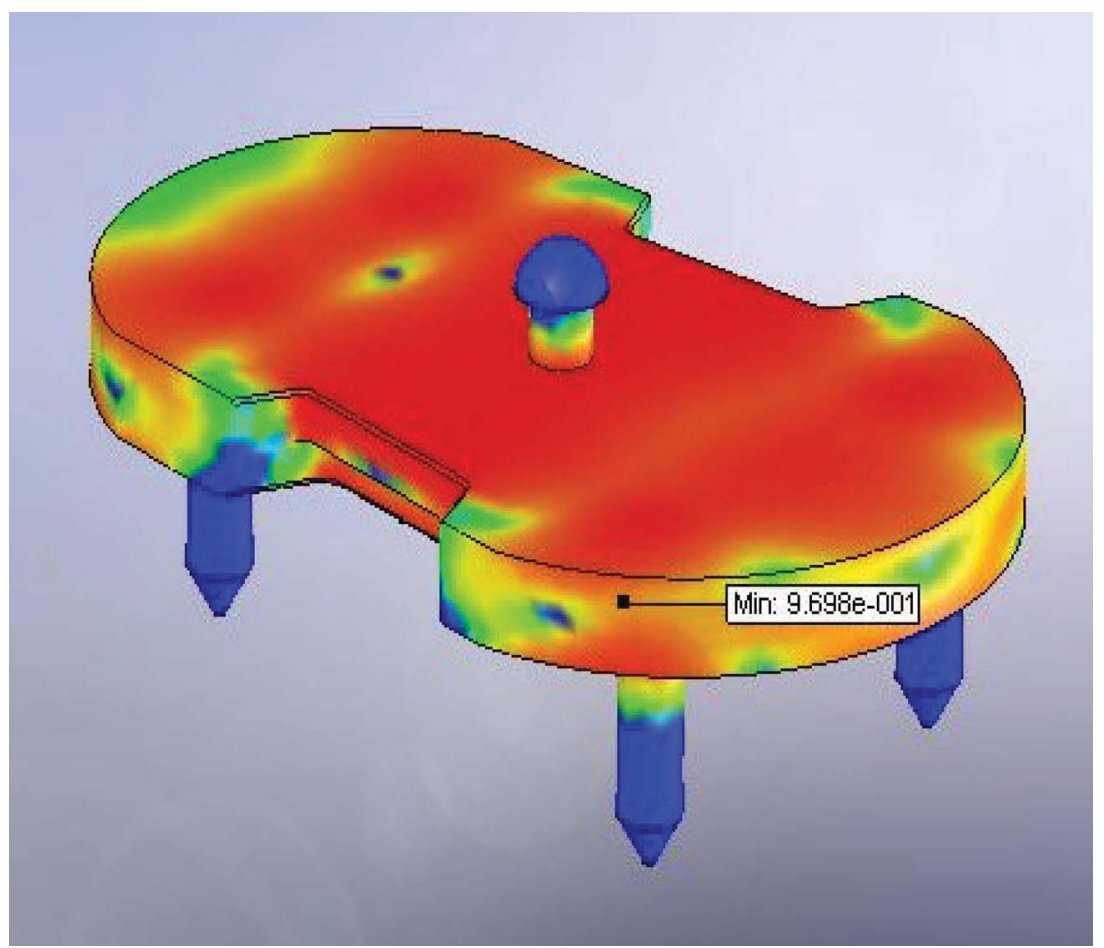

Figure 11. Max. von Mises stress - tibial component.

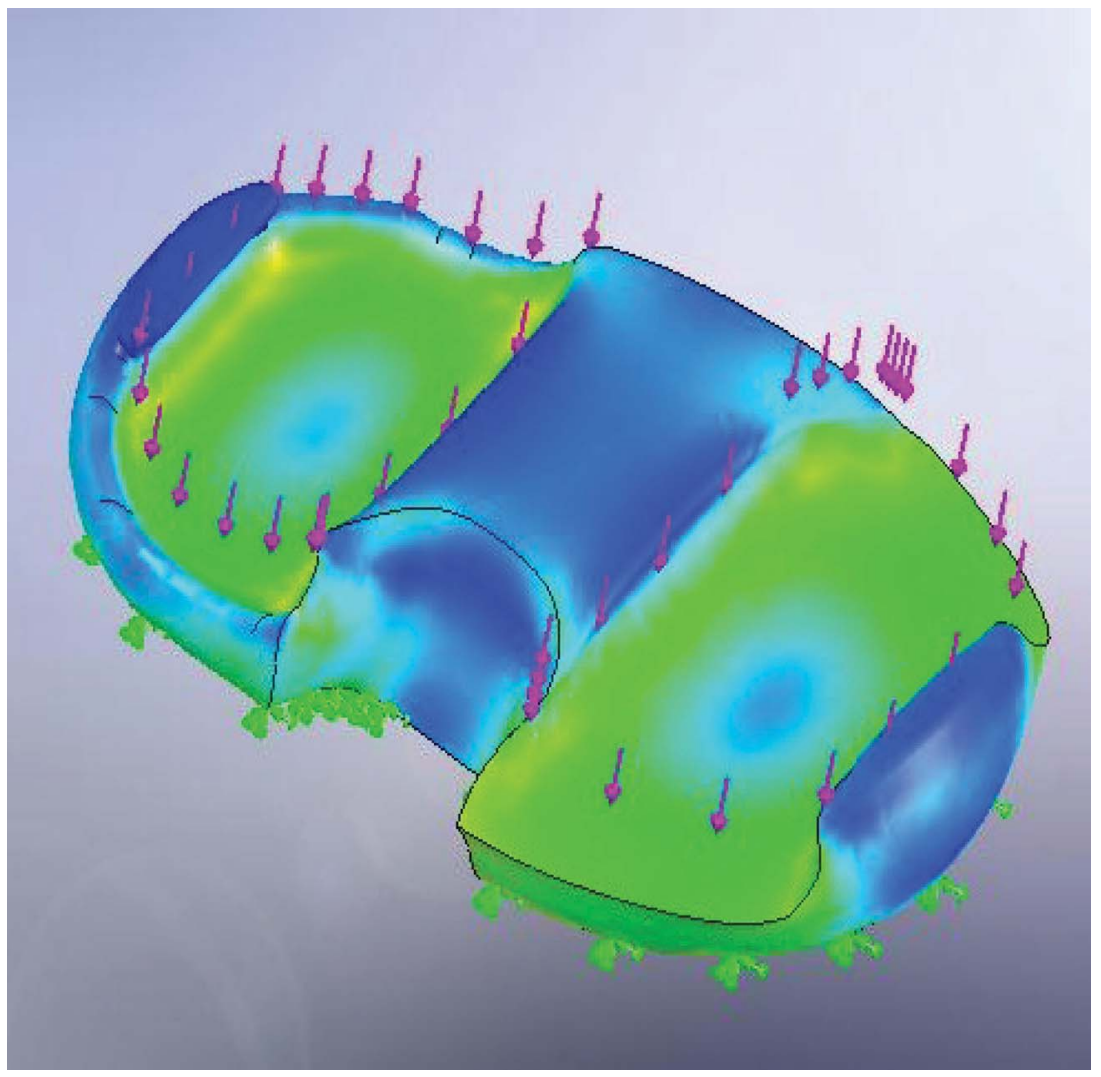

Figure 12. Static nodal stress - PE insert. 
Table 16. PE insert component description.

\begin{tabular}{ccccc}
\hline No. & Body name & Material & Mass & Volume \\
\hline 1 & Meniscal insert & UHMWPE & $0.0404991 \mathrm{lb}$ & $1.20533 \mathrm{in}^{3}$ \\
\hline
\end{tabular}

element codes are less complicated than many of the word processing and spreadsheet packages found on modern microcomputers. Nevertheless, they are complex enough that most users do not find it effective to program their own code. A number of pre-written commercial codes are available. FEA.

COSMOS software was used in this research to perform

\subsection{Loading conditions for the analysis}

The knee joint in normal conditions gets loaded with up to 2 to 3 times the body weight. The maximum load that the knee joint gets is up to 8 times the body weight. (Sivarasu and Mathew 2007). We have taken as the load 10 times the body weight. The weight over a single knee is only half the maximum load as the load is shared between the two knee joints. But for the analysis, we have taken the full load of 10 times the body weight considering that the patient is standing on one leg.
Table 17. PE insert component meshing information.

\begin{tabular}{ll}
\hline Jacobian check: & 4 Points \\
\hline Element size: & $2.7041 \mathrm{~mm}$ \\
Tolerance: & $0.13521 \mathrm{~mm}$ \\
Quality: & High \\
Number of elements: & 8990 \\
Number of nodes: & 14,416 \\
\hline
\end{tabular}

The loading conditions are shown in Table 5.

\subsection{FEA the femoral component}

The femoral component has the most complex design in the artificial knee. The femoral component description and meshing information are shown in Tables 6 and 7. For our analysis we have chosen 28 loading points and 2 restraints.

\subsubsection{Loading the component}

The loading is incremented in terms of $50 \mathrm{~kg}$ starting from $50 \mathrm{~kg}$ to $700 \mathrm{~kg}$. That would be approximately $1.8 \mathrm{kgf}$ load on each loading point for every load of $50 \mathrm{~kg}$ as shown in Figures 4-7; Tables 8-10; Charts 1-3;

\subsection{FEA of the tibial component}

The tibial component acts in the momentum balance in the design of the artificial knee. For our analysis we have

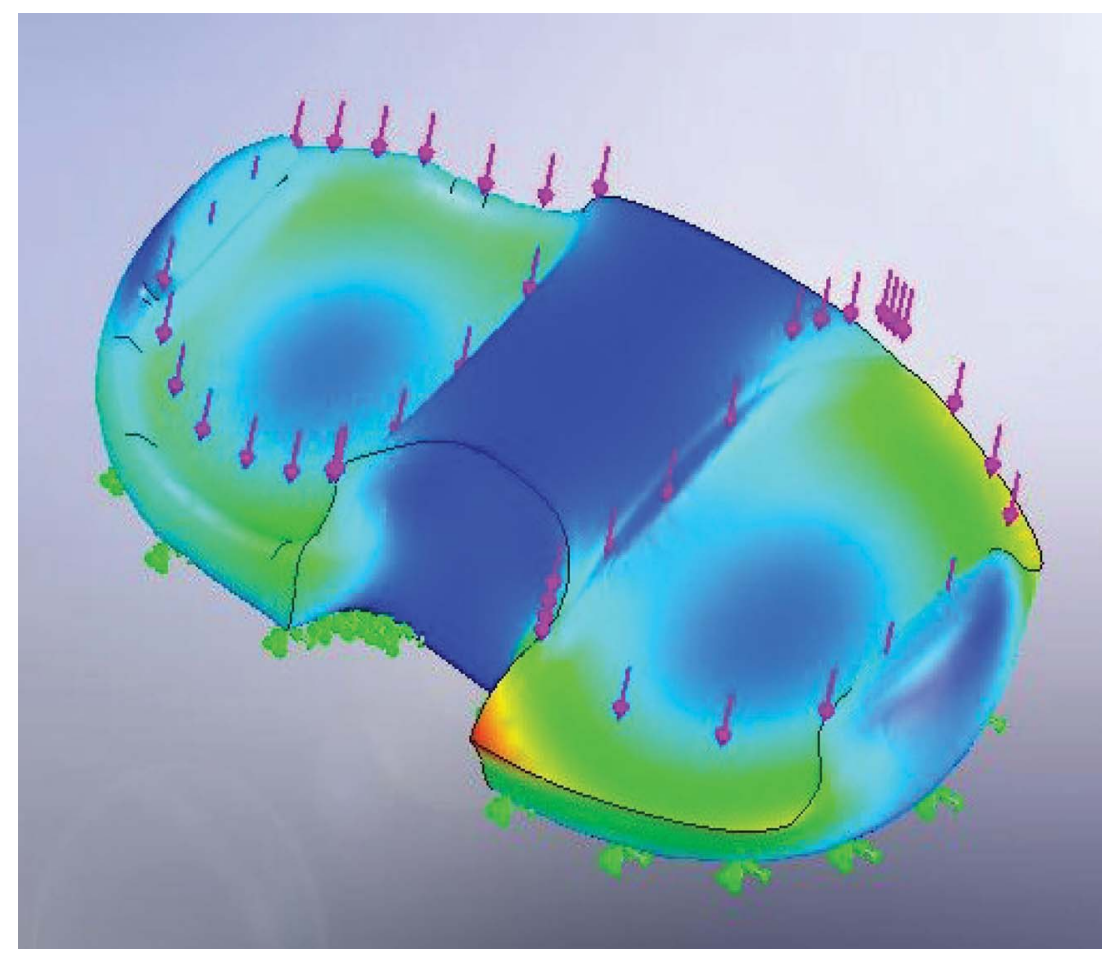

Figure 13. Static displacement $-\mathrm{PE}$ insert. 
Table 18. Static displacement results.

\begin{tabular}{lccccc}
\hline Name & Type & Min & Location & Max & Location \\
\hline Displacement & $\begin{array}{c}\text { Resultant } \\
\text { displacement }\end{array}$ & $0 \mathrm{~m}$ & $\begin{array}{c}(-1.72877 \mathrm{~mm}, \\
0 \mathrm{~mm}, 1 \mathrm{~mm})\end{array}$ & $1.80263 \mathrm{e}-005 \mathrm{~m}$ & $\begin{array}{c}(-9.82897 \mathrm{~mm}, \\
12.8297 \mathrm{~mm},\end{array}$ \\
& & & & Node: 202 & \\
& & Node: 51 & & & \\
\hline
\end{tabular}

Table 19. Static strain results.

\begin{tabular}{|c|c|c|c|c|c|}
\hline Name & Type & Min & Location & Max & Location \\
\hline \multirow[t]{2}{*}{ Strain } & $\begin{array}{l}\text { Equivalent } \\
\text { strain }\end{array}$ & $7.33804 \mathrm{e}-006$ & $\begin{array}{l}(30.1021 \mathrm{~mm}, \\
12.0926 \mathrm{~mm} \\
-7.75031 \\
\mathrm{~mm})\end{array}$ & 0.00118532 & $\begin{array}{l}(10.2657 \mathrm{~mm}, \\
0.688369 \mathrm{~mm}, \\
-17.6769 \\
\mathrm{~mm})\end{array}$ \\
\hline & & Element: 3115 & & Element: 2227 & \\
\hline
\end{tabular}

Table 20. Max. von Mises stress results.

\begin{tabular}{lccccc}
\hline Name & Type & Min & Location & Max & Location \\
\hline \multirow{2}{*}{ Stress } & VON: von & $38754.8 \mathrm{~N} / \mathrm{m}^{2}$ & $(29.7798 \mathrm{~mm}$, & $8.34861 \mathrm{e}+006$ & $(-9.82897 \mathrm{~mm}$, \\
& & $12.4148 \mathrm{~mm}$, & $\mathrm{N} / \mathrm{m}^{2}$ & $0 \mathrm{~mm},-21.5$ \\
& Mises stress & & $7.71442 \mathrm{~mm})$ & Node: 207 & $\mathrm{~mm})$ \\
& & & & \\
& Node: 14,383 & &
\end{tabular}

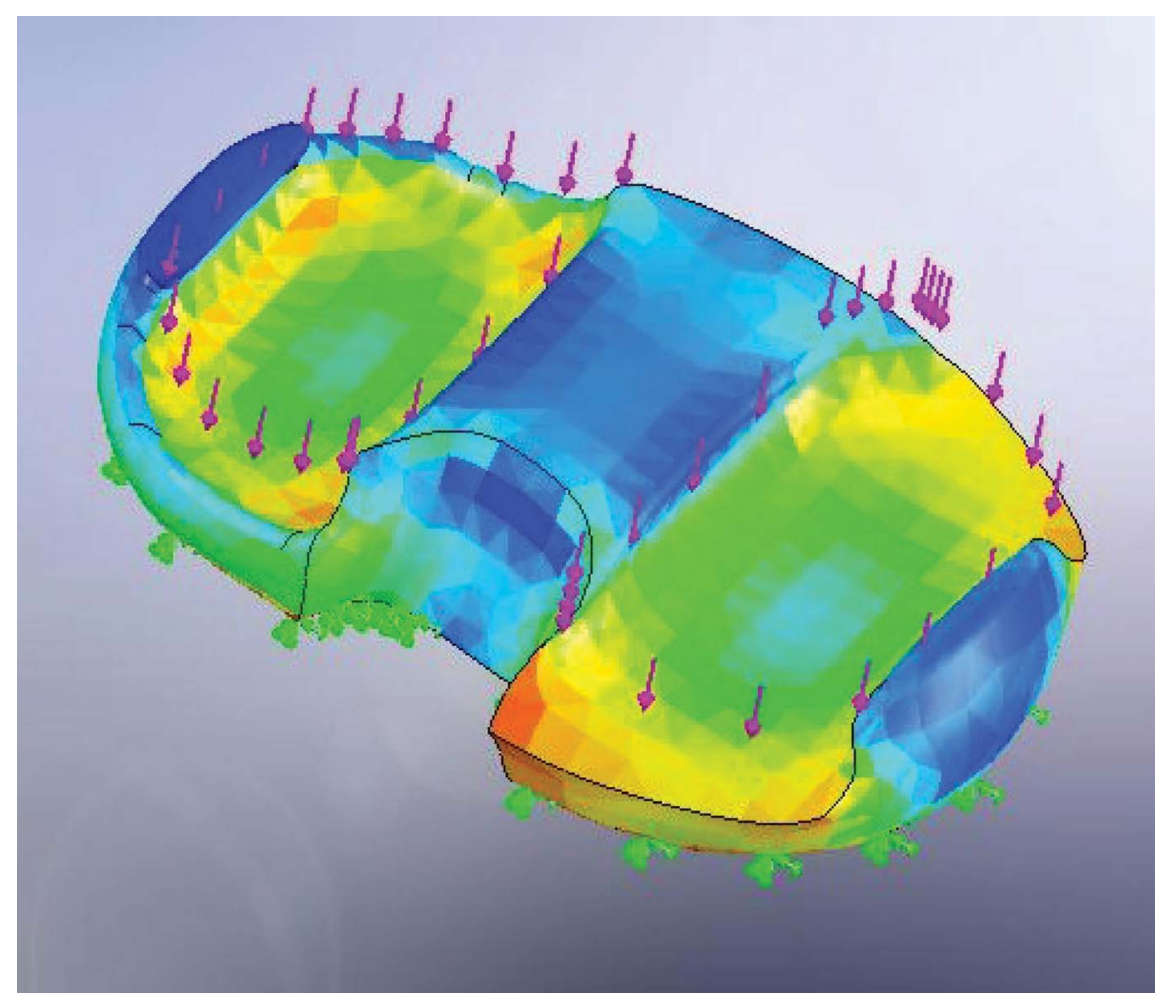

Figure 14. Static strain - PE insert. 


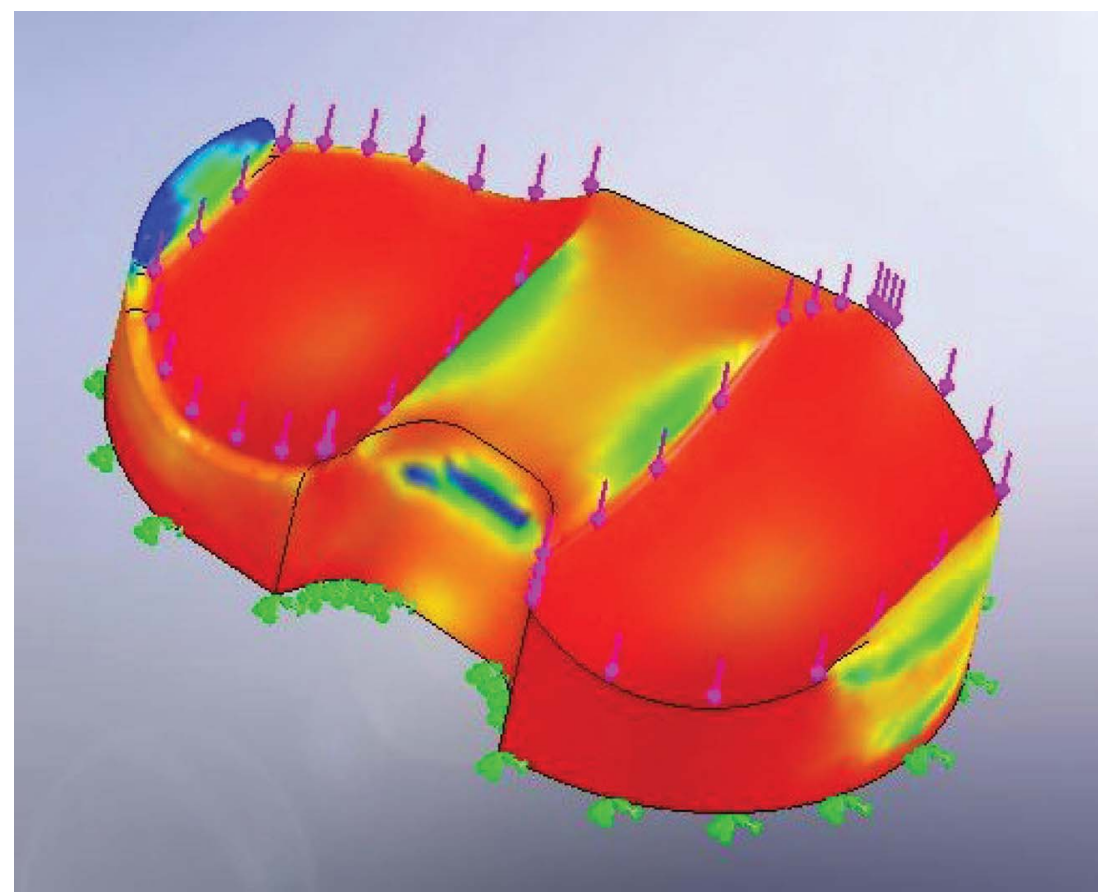

Figure 15. Max. von Mises stress - PE insert.

chosen single loading point and 4 restraints as shown in Tables 11 and 12.

\subsubsection{Loading the component}

The loading is incremented in terms of $50 \mathrm{~kg}$ starting from $50 \mathrm{~kg}$ to $700 \mathrm{kgs}$ as shown in Figures $8-11$ and Tables $11-15$.

\subsection{FEA of the meniscal insert}

The meniscal component provides the rolling and gliding interface for the metal components of the artificial knee. For our analysis we have chosen 2 loading areas, ie., the condylar contact areas. The FEA details are shown in Tables $16 \& 17$.

\subsubsection{Loading the component}

Total number of loading points: 2

Total number of restraints: 1

The loading is incremented in terms of $50 \mathrm{~kg}$ starting from $50 \mathrm{~kg}$ to $700 \mathrm{~kg}$. A maximum load of $350 \mathrm{~kg}$ is applied over each loading point as shown in Figures $12-15$ and Tables 18-20.

\section{Results and discussion}

The FEA results have shown that the design with the given material properties behaves very well within the linear mechanical limits. The high concentrations of the stresses on the models are seen in the cases of extreme loads such as
10 times the body weight. But considering the fact that most of the times the loading is within 3 to 4 times the body weight. So the accumulation of the static stress would not affect the designs.

The linear behaviour of the models is shown in the Charts $1-3$. The results have been encouraging in making the author move the model for prototyping.

\section{Conclusion}

Thus the novel high flexion knee design was subjected on to extreme loads and analysed using FEM techniques and the results have been satisfactory.

\section{References}

Karsh ME, Ploeg H-L. 2005. How does normal flexion patello femoral contact area changes before and after deep knee flexi on. Summer Bio-Engineering conference, June 22-26, 2005, Vail Cascade Resort \& Spa: Vail, Colorado.

Marina E. Karsh, Heidi-Lynn Ploeg, How does normal flexion Patello femoral contact area changes before and after deep knee flexi on. Summer Bio-Engineering conference, June 2226, 2005, Vail Cascade Resort \& Spa: Vail, Calorado.

Raymond P. Robinson. 2005. The early innovators of today's resurfacing condylan knees. The Journal of Arthroplasty Vol. 20, No. 1, Suppl. 1.

Sivarasu S, Mathew L. 2000. Modelling an artificial knee for customized needs of Indian population. INCOB-08, VITU, 6-8: $138-139$

Sivarasu S, Mathew L. 2007. Design of an artificial high flexion knee. Life Science Systems and Applications Workshop, 2007. LISA 2007. USA: IEEE/NIH; 2007 Nov 8-9; 112-115. 

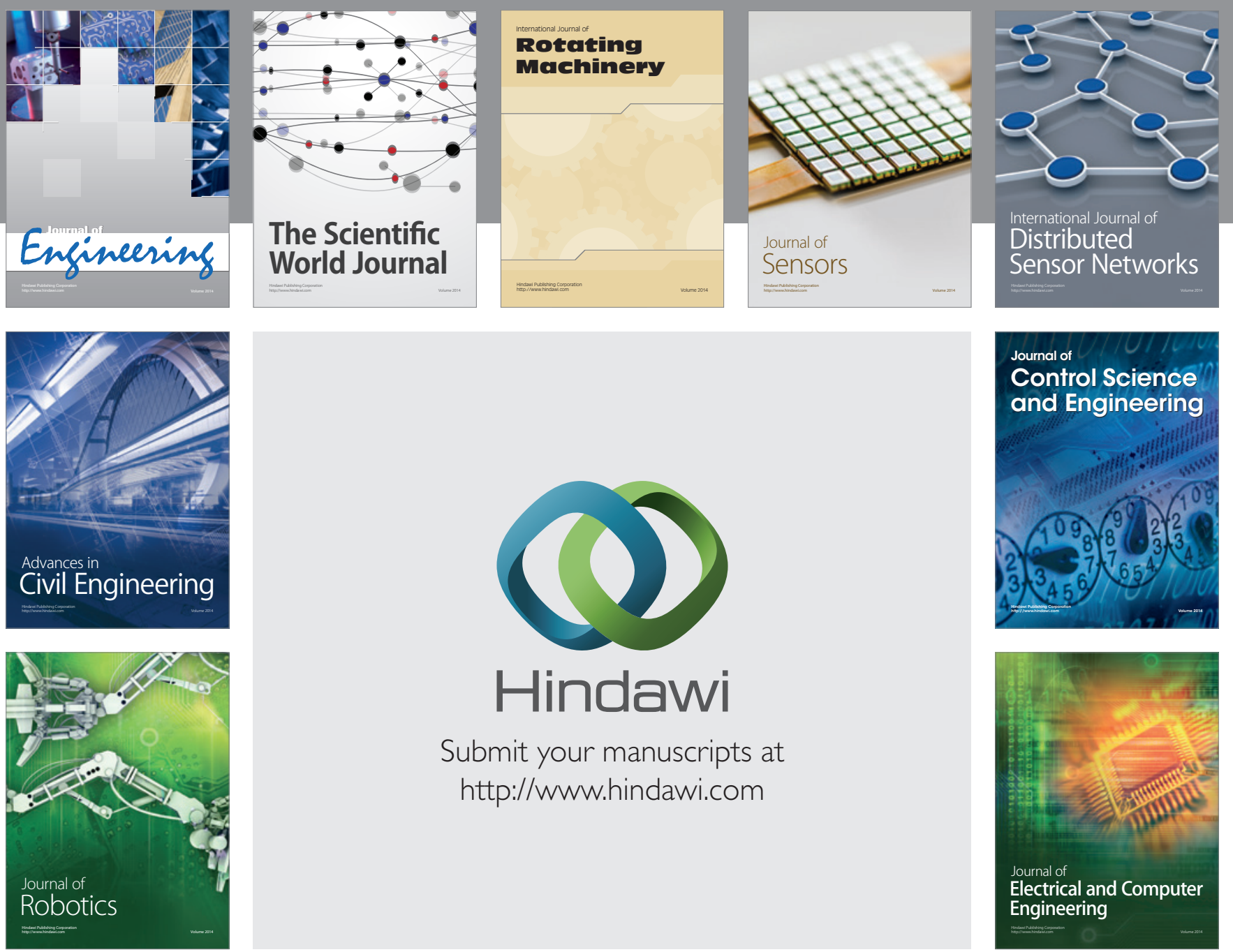

Submit your manuscripts at

http://www.hindawi.com
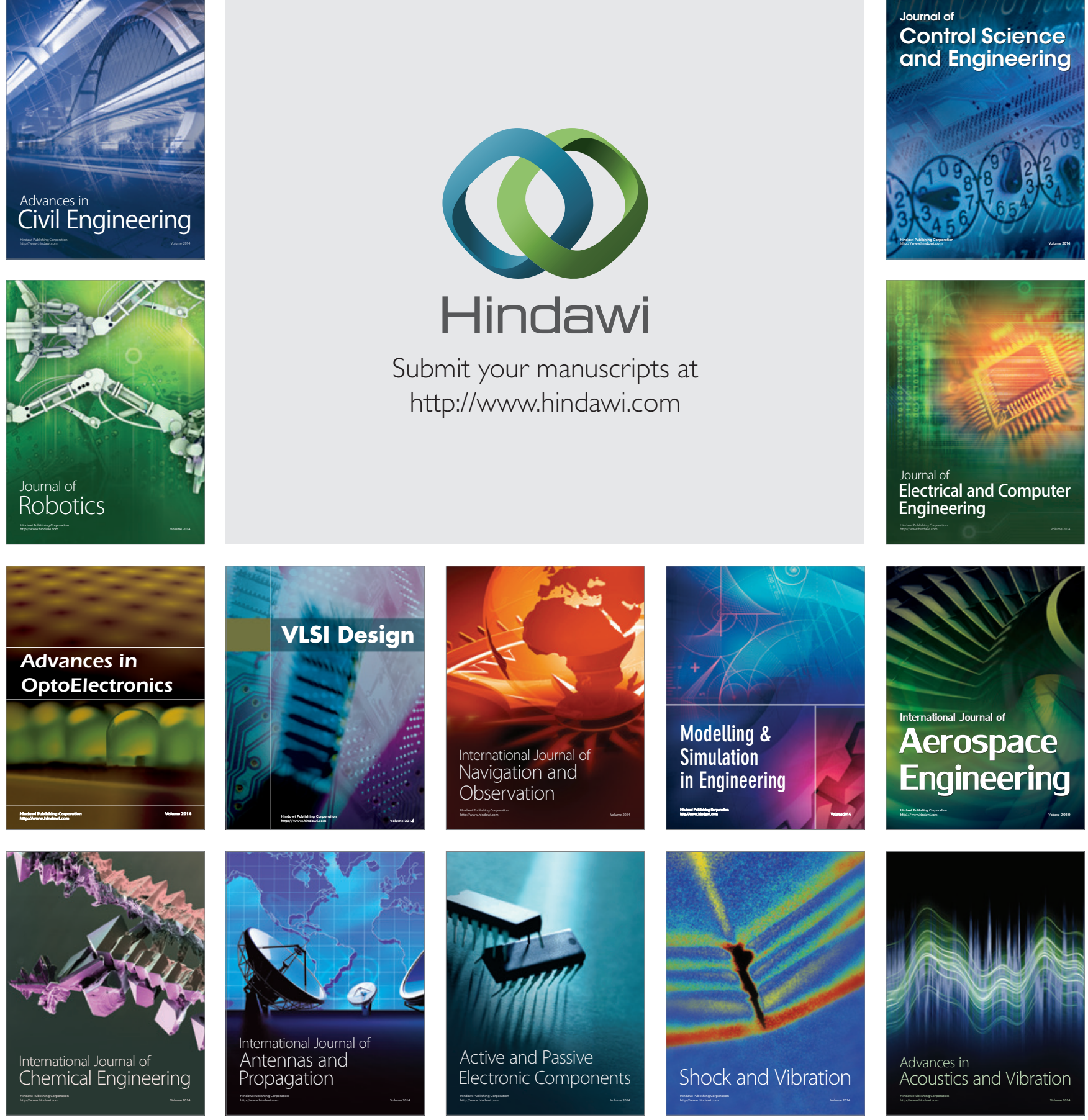